\title{
Powdered intermediate of yacon as a prebiotic ingredient of bakery products
}

\author{
N. M. Derkanosova, S.A. Shelamova, O.A. Vasilenko*, V.K. Gins, and N.I. Derkanosov \\ ${ }^{1}$ Voronezh State Agrarian University named after Emperor Peter the Great, Voronezh 394087, Russia \\ ${ }^{2}$ Federal scientific centre of vegetable growing, VNIISSOK settlement, Moscow region 143080, Russia \\ ${ }^{3}$ Association of Voronezh regional chamber of commerce and industry, Voronezh 394018, Russia
}

\begin{abstract}
The current stage of consumer market development is described by increasing interest in healthy food products, specialized, and functional purpose foods. In these conditions, the solution of the problem of the correction of the composition, while preserving the taste, aroma and other consumer characteristics, is of particular importance. The complex of organoleptic, physicochemical, and microbiological tests confirmed the technological feasibility of using yacon powder in bakery technology made of a mixture of rye and wheat flour. The studies on the composition of yacon powder, its effect on the growth and development of lactic acid bacteria demonstrate the possibility of using yakon powder as a functional food ingredient with a prebiotic effect. The results obtained are confirmed by a comparative characteristic of the quality and composition of bread made of the mixture of rye and wheat flour of the control and experimental samples with the addition of powdered yacon semi-finished product.
\end{abstract}

\section{Introduction}

Interest in a healthy diet is caused by the possibility of not only providing the body's energy needs at the expense of consumed nutrients, but also maintaining it in a physiologically active state. Accordingly, while discussing this issue, it is advisable to pay attention to raw ingredients possessing a property or a set of properties that ensure both the manufacturability of processes and the production of innovative food products [1-4]. From this point of view, it is of interest to study the potential of introduced cultures, including the yacon [5].

Yacon (genus Polymnia, species Polymnia Sonchifolia) in included in the aster family (Compositae). It grows on various soil types and regions between the $40^{\circ}$ of southerly latitude and the $45^{\circ}$ of northerly latitude [6]. Root tubers of yacon can be as long as $20 \mathrm{~cm}$ and $10 \mathrm{~cm}$ in diameter. They are purplebrown from the outside and white or yellow inside. They are crunchy and their taste is refreshingly sweet.

The yakon rhizomes and root tubers accumulate carbohydrates, particularly, inulin, which can be transformed into fructose and other compounds in the form of fructans in the process of storage or hydrolytic decomposition. Yakon freshly harvested root tubers contain $37.5 \%$ of fructose per dry matter [6]. The composition of root tubers includes amides, amino acids. Yacon protein significantly exceeds the protein content of wheat, corn, soybean in terms of essential amino acids concentration [6]. Besides, yacon root tubers are able to accumulate selenium up to $1.1 \mathrm{mg} / \mathrm{kg}$. This feature of yacon can be used to produce dietary products containing the most important antioxidant, selenium. [6].

The composition of yakon, rich in physiologically important nutrients, allowed it becoming promising in food technology, including bakery products associated with mass consumption. In this connection, the purpose of this work was to determine the potential of yakon processed products as an enriching ingredient in bakery products that can increase the functionality of the finished food product and intensify its technological process [7].

From a number of works it is known about the use of yacon processing products in bakery technology [8]. It has been found that yakon puree in the composition of the nutrient mixture of liquid rye sourdough intensifies the vital activity of lactic acid bacteria and yeast while maintaining the symbiotic relationship between them. Probably, the intensification of processes is favored by the preferential consumption of fructose by yeast cells as compared to the key technological disaccharide maltose, as well as the addition of magnesium, phosphorus, and glutamic acid associated with yacon chemistry [8].

The pre-hydrolyzed yacon puree has even more prominent positive effect on the starter microflora and the quality of the finished products [8]. However, the use of yacon processing products in the form of puree and hydrolyzed puree has difficulties with its practical implementation due to the high moisture content of the product and, accordingly, storage problems and inexpediency of transportation. Besides, high humidity is a limiting factor in the dosage of puree and, accordingly, does not allow fully using its potential as a functional

* Corresponding author: ewa007@yandex.ru 
food ingredient. In this connection, in our further studies, the feasibility of obtaining and using dried yacon products was considered [7].

\section{Materials and methods}

Yakon Yudinka varieties, obtained from the All-Russian Research Institute for Vegetable Plant Breeding and Seed Production, were used in the studies. The preparation of a powdered semifinished product was carried out by convective drying of the previously washed and cut yacon root tubers, followed by grinding to a grain size of $0.5 \mathrm{~mm}$.

The research of the chemical composition of yacon products were carried out using standardized methods. Microbiological tests were performed by inoculation of pre-activated lyophilized cultures of lactic acid bacteria and liquid rye ferment with brewing for wort-agar with a solids content of $12 \%$. The inoculations were incubated in a thermostat at $37^{\circ} \mathrm{C}$ for 3 days [9].

\section{Results and discussion}

The description of organoileptic indicators and the chemistry of powdered semi-finished yacon product is predented in Table 1.

Table 1. Description of powdered semi-finished yacon product

\begin{tabular}{|c|l|c|}
\hline$\#$ & \multicolumn{1}{|c|}{ Indicator } & $\begin{array}{c}\text { The description of powdered } \\
\text { semi-finished yacon product }\end{array}$ \\
\hline 1 & Color & Light creamy, monochrome \\
\hline 2 & Smell & Fruity, less pronounced \\
\hline 3 & Taste & $\begin{array}{l}\text { Sweet, bold, fruity } \\
\text { without lumps }\end{array}$ \\
\hline 4 & Consistency & $7.1 \pm 0.1$ \\
\hline 5 & Moisture content, $\%$ & \\
\hline & $\begin{array}{l}\text { Mass content, } \% \text { per } \\
\text { dry matter }\end{array}$ & $3.8 \pm 0.08$ \\
\hline 6 & protein & $1.3 \pm 0.03$ \\
\hline 7 & fat & $89.1 \pm 1.2$ \\
\hline 8 & carbohydrates & $46.6 \pm 0.8$ \\
\hline & including & $4.8 \pm 0.1$ \\
\hline 9 & inulin & $25.8 \pm 0.5$ \\
\hline 10 & glucose & $3.1 \pm 0.06$ \\
\hline 11 & fructose & $3.1 \pm 0.05$ \\
\hline 12 & sucrose & $4.7 \pm 0.8$ \\
\hline 13 & fibre & \\
\hline 14 & ash & $237 \pm 4.4$ \\
\hline & Content, mg/100 g & \\
\hline 15 & calcium & $215 \pm 4.2$ \\
\hline 16 & phosphorus & $116 \pm 2.0$ \\
\hline 17 & magnesium & Hе опр. \\
\hline 18 & potassium & $11.6 \pm 0.2$ \\
\hline 19 & ferrum & $0.58 \pm 0.01$ \\
\hline 20 & zinc & $215 \pm 4.2$ \\
\hline 21 & manganese, \\
mcg/100 g & \\
\hline 22 & cuprum, mcg/100 g & \\
\hline & & \\
\hline
\end{tabular}

As the results of the study showed, powdered semifinished yacon product has a light cream colour in the traditional colour range of bakery products, and pronounced sweet taste. It has high content of inulin and fiber and ash, which confirms the feasibility of using yakon products in bread technology.

To confirm the prebiotic properties of yacon, series of model experiments were carried out in which lactic acid bacteria (LAB) were inoculated on agar media with malt wort with a $12 \%$ (control) mass fraction of dry substances (extract) from aacon (experiment).

The yacon extract was prepared by mixing the yacon powder and water in mass fraction proportion of 1:9, extraction of water-soluble substances at $80^{\circ} \mathrm{C}$ for 30 minutes and subsequent filtration. The solids content of the extract-agar was $8 \%$.

Lacrobacillin was used as a source of LAB which is dry lyophilisate containing microbial mass of lactobacteria of the strains Lactobacillus plantarum 8PA3, L. plantarum 38, L. fermenti 90T-C4, L. fermenti 39 , lyophilised in cuilture medium with addition of protective sucrose-gelatin or sucrose-gelatin-milk medium.

The results of the model experiments are demonstrated in Figures 1-4.

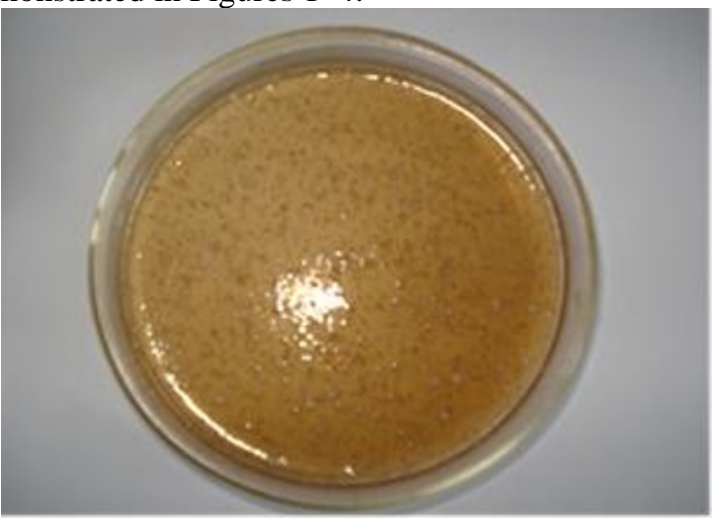

Fig. 1. LAB (lactobacterin) inoculation in wort-agar (control)

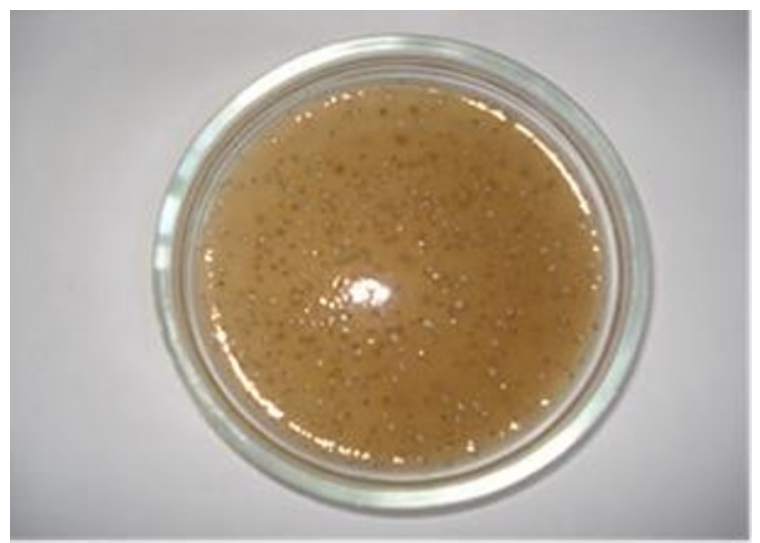

Fig. 2. LAB (lactobacterin) inoculation in agar extract (experiment)

In both of the studied variants, one of the characteristic types of LAB colonies was found during deep inoculation on a solid nutrient medium - delicate, white-colored, resembling a wad of cotton. Considering the best growth of LAB without air access, characteristic of facultative anaerobes, single rounded colonies were found on the surface, with a smooth surface, slightly gibbose, grayish in color. 
In general, as demonstrated by the test results, the medium based on the yacon extract is not inferior to the malt wort as food sources for the LAB growth and development. It is known that precisely agarized malt wort is recommended to be used for the extraction of lactic acid bacteria [5]. Thus, based on the definition of a prebiotic as a substance with selective stimulation of growth and / or increase in the biological activity of the normal intestinal microflora, it can be assumed that the yacon has prebiotic properties.

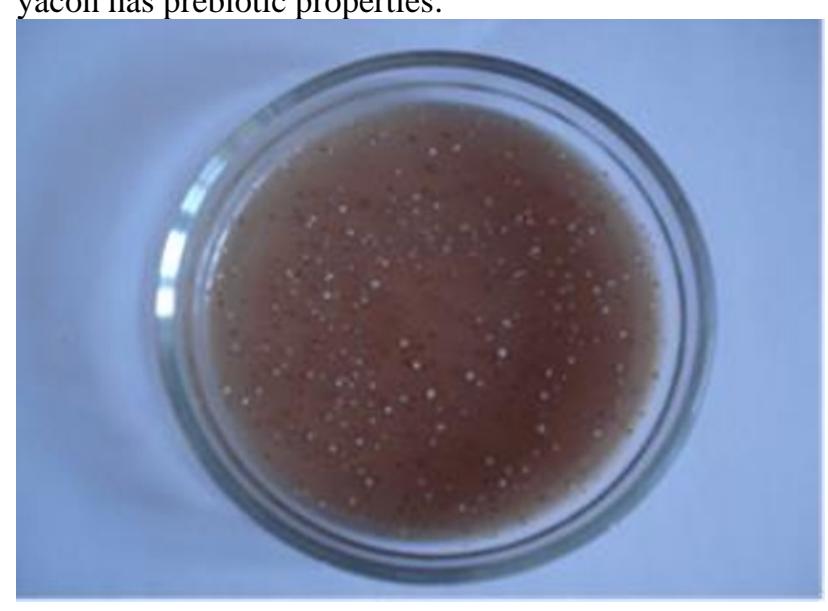

Fig. 3. LAB inoculation in wort-agar. (control)

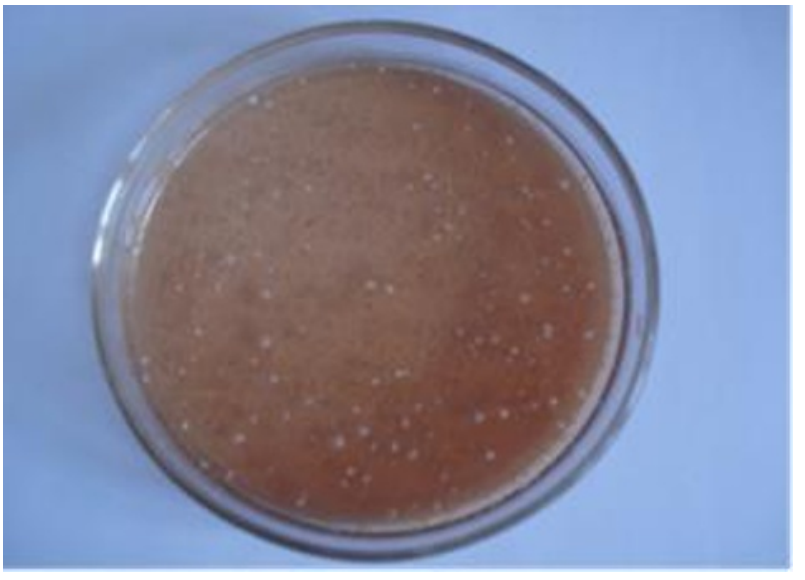

Fig. 4. LAB inoculation in agar extract. (experiment)

The second series of model experiments was aimed at proving the technological feasibility of using powdered yacon semi-product as an ingredient for bread of mixture of rye and wheat flour. Inoculations of lactic acid bacteria and yeast traditionally used for making liquid rye starter were placed in agarized media - wortagar (control) and extract-agar (experiment). The source of microflora was liquid brewing rye sourdough the microflora of which was represented by lactic acid bacteria L. plantarum-30, L. casei-26, L. brevis-1, L. fermenti-34 and yeast S. cerevisiae L-1 [10]. The results of the research are presented in fig. 3, 4 .

On the surface of the agar media of the control and experimental samples, colonies are described with round shape, white color, juicy consistency, oily, cultural characteristics of which are characteristic of S. cerevisiae yeast. At the same time, the number of colonies on the extract-agar is more visible than on the wort-agar. This also confirms the technological feasibility of using yacon products in bakery technology.

\section{Conclusion}

The preliminary results were confirmed by the experimental baking of bread of the mixture of rye and wheat flour with addition of powdered yacon semifinished product. The rational recipe of the bakery product is found by the method of central composite rotary uniform planning (Table 2 ).

When processing the results of the experiment planning, the dispersion homogeneity was checked by the Cochren criterion, the significance of the coefficients in the regression equations was proved by the Student criterion and the adequacy of the equations was checked using the Fisher criterion [10].

The experiments were repeated 3-5 times, and the arithmetical mean values were used for obtained result calculations. Statistical analysis of the regression equations was carried out according to the program embedded in the experimental design matrix according to the selected method using the application software package. Only the results reproducing in each experiment were discussed. The consistence results were considered with the significance level of $q=0.05$.

The following are selected as the key factors:

- $\mathrm{X}_{1}$ - dosage of the powdered yacon semi-product, $\mathrm{kg}$ per $100 \mathrm{~kg}$ of flour;

- $\mathrm{X}_{2}$ - dosage of the liquid rye starter, $\mathrm{kg}$ per $100 \mathrm{~kg}$ of flouro0.

These factors are compatible and uncorrelated with each other. Their variation in the formulation determines the main processes characteristic of the technology of production of bread made of the mixture of rye and wheat flour - alcohol and lactic acid fermentation [9]. The limits of variation of the tested factors are shown in table 2.

Table 2. Factor variation limits

\begin{tabular}{|c|c|c|}
\hline \multirow{2}{*}{ Planning level } & \multicolumn{2}{|c|}{ Variation limits } \\
\cline { 2 - 3 } & $\begin{array}{c}\mathrm{X}_{1}, \mathrm{~kg} / 100 \mathrm{~kg} \\
\text { of flour }\end{array}$ & $\begin{array}{c}\mathrm{X}_{2}, \mathrm{~kg} / 100 \mathrm{~kg} \\
\text { of flour }\end{array}$ \\
\hline Basic level & 6.0 & 71.0 \\
\hline Variation interval & 3.0 & 6.0 \\
\hline Top level & 9.0 & 77.0 \\
\hline Bottom level & 3.0 & 65.0 \\
\hline Top extremum & 10.2 & 79.5 \\
\hline Bottom extremum & 1.8 & 62.5 \\
\hline
\end{tabular}

The choice of the variation limits of liquid rye starter is based on the recommendations of the unified instruction [11] and of the powdered prefabricated yacon - on a preliminary series of experiments.

The other formulation components are taken from variants mostly used by the industry:

- the mass proportion of rye break flour and wheat first grade flour is 50:50;

- the dosage of pressed yeast is $0.5 \mathrm{~kg}$ per $100 \mathrm{~kg}$ of flour;

- the dosage of cooking salt is $1.5 \mathrm{~kg}$ per $100 \mathrm{~kg}$ of flour. 
The dough was kneaded on liquid rye sourdough with malt with $80 \%$ of water, the breeding cycle of which was carried out using dry lactobacterin and pure yeast culture S. cerevisiae L-1 [11]. The dough with a temperature of $28 \ldots 30{ }^{\circ} \mathrm{C}$ on the starter cultures was fermented to the final acidity of 9-12 degrees.

The baked samples were examined by physicochemical parameters selected as criteria for assessing the influence of the tested factors:

- $\mathrm{y}_{1}-$ crumb porosity. $\%$;

- $\mathrm{y}_{2}$ - crumb acidity, degrees.

The experiment program is inserted in the experiment planning matrix (Table 3).

Table 3. Experiment planning matrix and results

\begin{tabular}{|c|c|c|c|c|c|}
\hline \multicolumn{2}{|c|}{$\begin{array}{c}\text { Codified factor } \\
\text { values }\end{array}$} & \multicolumn{2}{c|}{$\begin{array}{c}\text { Natural factor } \\
\text { values, kg/100 kg } \\
\text { of flour }\end{array}$} & \multicolumn{2}{c|}{$\begin{array}{c}\text { Output } \\
\text { parameters }\end{array}$} \\
\hline $\mathrm{X}_{1}$ & $\mathrm{X}_{2}$ & $\mathrm{X}_{1}$ & $\mathrm{X}_{2}$ & $\mathrm{y}_{1}$ & $\mathrm{y}_{2}$ \\
\hline-1 & -1 & 3.0 & 64.0 & 60.3 & 6.2 \\
\hline-1 & +1 & 3.0 & 76.0 & 63.4 & 8.4 \\
\hline+1 & -1 & 9.0 & 64.0 & 62.8 & 5.8 \\
\hline+1 & +1 & 9.0 & 76.0 & 68.8 & 8.0 \\
\hline-1.414 & 0 & 1.8 & 70.0 & 62.0 & 7.6 \\
\hline+1.414 & 0 & 10.2 & 70.0 & 65.4 & 7.4 \\
\hline 0 & -1.414 & 6.0 & 59.9 & 60.8 & 5.6 \\
\hline 0 & +1.414 & 6.0 & 80.2 & 61.5 & 9.0 \\
\hline 0 & 0 & 6.0 & 70.0 & 64.4 & 7.4 \\
\hline 0 & 0 & 6.0 & 70.0 & 63.8 & 7.5 \\
\hline 0 & 0 & 6.0 & 70.0 & 63.0 & 7.6 \\
\hline 0 & 0 & 6.0 & 70.0 & 63.9 & 7.3 \\
\hline 0 & 0 & 6.0 & 70.0 & 63.0 & 7.5 \\
\hline
\end{tabular}

After the statistical processing of the experimental data the regression equations are obtained that adequately describe the influence of the tested factors on the bread quality:

$$
\begin{gathered}
Y_{1}=63,635+1,53 \cdot X_{1}+1,28 \cdot X_{2}+0,775 \cdot X_{1} \cdot X_{2}+0,365 \cdot X_{1}{ }^{2} \\
Y_{2}=7,563-0,135 \cdot X_{1}+1,151 \cdot X_{2}-0,056 \cdot X_{1}{ }^{2}-0,156 \cdot X_{2}{ }^{2}(2)
\end{gathered}
$$

The analysis of the regression equations allows identifying factors affecting the process in question. Thus, the dosage of powdered semi-finished product of yacon has the greatest positive effect on the bread porosity and the dosage of starter affects the acidity. The dosage of the starter culture also has a positive effect on the porosity of the bread, while the acidity and dosage of the yacon powder are inversely proportional.

The optimal values of the considered factors were determined by the ridge analysis method based on the method of uncertain Lagrange multipliers [10].

The I value is affected by the limitations defined by the Horl parameter. The valid values of the indefinite Lagrange multiplier lie in the range:

$$
2.1<1<0.9
$$

for the output parameter of crust porosity;

$$
2.0<1<4.0
$$

for the output parameter of acidity.

Taking the I values from the intervals (3), (4) we defined the optimal proportion of the component in the formulations. As the obtained values of U2 lie within the interval of 7.0-7.5 degrees, the final choice of the formulation was based on the crust porosity.
Processing of experimental data, including optimization, was carried out using the specially developed Opto software package.

The translation of the coded values of factors to natural ones allowed defining the following factor values:

- the dosage of the powdered yacon semi-product is $8.5 \mathrm{~kg} / 100 \mathrm{~kg}$ of flour;

- the dosage of the liquid rye starter with malt is $70.8 \mathrm{~kg} / 100 \mathrm{~kg}$ of flour.

To unify the production process, the starter dosage of of $71.0 \mathrm{~kg} / 100 \mathrm{~kg}$ of flour was applied. A similar dosage was recommended by [11] for the production of most bread types from a mixture of rye and wheat flour with started with malt.

This way the formulation composition of bread from a mixture of rye and wheat flour with the introduction of powdered yacon semi-product was proved (Table 4).

Table 4. Bread recipe of the mixture of rye and wheat flour with yacon

\begin{tabular}{|l|c|}
\hline \multicolumn{1}{|c|}{ Raw material type } & $\begin{array}{c}\text { Raw material } \\
\text { consumption. } \mathrm{kg}\end{array}$ \\
\hline Wheat baking flour. first grade & 50.0 \\
\hline Rye baking flour. medium & 50.0 \\
\hline Powdered semi-product of yacon & 8.5 \\
\hline Baking pressed yeast & 0.5 \\
\hline Cooking salt & 1.5 \\
\hline Total & 110.5 \\
\hline
\end{tabular}

Comparative assessment of the bread quality indicators is given in Table 3. The most common bread in the consumer market Darnitsky was used as the control sample.

As the results of the experiment baking showed bread made of the mixture of rye and wheat flour with addition of powdered semi-finished product of yacon has the best porosity, volume, structural and mechanical properties during storage. In addition, it does not lose the traditional look, taste and aroma inherent in this group of bakery products.

Studies of the chemical composition of the control and experimental samples showed that compared to the control sample bread made of the mixture of rye and wheat flour with powdered yacon semi-finished product has higher concentration of dietary fiber, calcium, phosphorus, potassium, iron, respectively by 5.5. 1.38 5.5. 1.38. 1.20. 1.89. 1.16 times. It is able to provide up to $20.9-26.6 \%$ of the organism's daily need for selenium. It contains $2.02 \mathrm{~g} / 100 \mathrm{~g}$ of inulin which together with other characteristics of the composition makes it possible to recommend the bread with the addition of yacon for the functional nutrition.

Thus the complex of performed organoleptic. Physicchemical and microbiological tests confirmed the technological feasibility of using yacon powder in production technology of the bread of mixture of rye and wheat flour. At the same time the studies of the yacon powder composition its influence on the growth and development of lactic acid bacteria allowed recommending yacon powder as a functional food ingredient with a prebiotic effect. 
Table 5. Bread recipe of the mixture of rye and wheat flour with yacon

\begin{tabular}{|c|c|c|}
\hline \multirow[t]{2}{*}{ Indicators } & \multicolumn{2}{|c|}{ Sample description } \\
\hline & control & $\begin{array}{l}\text { the sample of the flour with addition of } \\
8.5 \% \text { of powdered yacon semi-product }\end{array}$ \\
\hline \multicolumn{3}{|l|}{ Appearance } \\
\hline shape & \multicolumn{2}{|c|}{ Standard bread shape matching the baking form. without mishape } \\
\hline surface & \multicolumn{2}{|c|}{ Rough. without cracks and erosions } \\
\hline color & \multicolumn{2}{|c|}{ Broun } \\
\hline \multicolumn{3}{|l|}{ Crumb state } \\
\hline thorough baking & \multicolumn{2}{|c|}{ Well baked not sticky. Not wet to the touch. resilient } \\
\hline thorough kneading & \multicolumn{2}{|c|}{ Without lumps and bad kneading } \\
\hline porosity & \multicolumn{2}{|c|}{ Well developed. without cavities and lumps } \\
\hline Taste & $\begin{array}{l}\text { Typical for Darnitsky bread. without foreign } \\
\text { taste }\end{array}$ & $\begin{array}{c}\text { Typical for bread of the mixture of rye and } \\
\text { wheat flour with light fruity taste }\end{array}$ \\
\hline Smell & $\begin{array}{c}\text { Typical for Darnitsky bread. without foreign } \\
\text { smell }\end{array}$ & $\begin{array}{l}\text { Typical for bread of the mixture of rye and } \\
\text { wheat flour with light fruity smell }\end{array}$ \\
\hline Crump moisture. \% & $48.2 \pm 0.5$ & $48.2 \pm 0.5$ \\
\hline Crump acidity. number & $7.0 \pm 0.1$ & $7.6 \pm 0.1$ \\
\hline Crump porosity. $\%$ & $63.8 \pm 1.0$ & $68.4 \pm 1.0$ \\
\hline Specific volume. $\mathrm{cm}^{3} / 100 \mathrm{~g}$ & $246.4 \pm 3.0$ & $264.8 \pm 3.0$ \\
\hline $\begin{array}{l}\text { Content of bisulfite binders. mg- } \\
\text { eq. } / 100 \mathrm{~g} \text { of the binder }\end{array}$ & $3.24 \pm 0.03$ & $3.92 \pm 0.03$ \\
\hline \multicolumn{3}{|l|}{ Elasticity after storage. h. KPa } \\
\hline 3 & $7.8 \pm 0.2$ & $9.6 \pm 0.3$ \\
\hline 24 & $6.4 \pm 0.2$ & $8.1 \pm 0.2$ \\
\hline 48 & $5.2 \pm 0.1$ & $6.5 \pm 0.2$ \\
\hline
\end{tabular}

\section{References}

1. I.A. Rogov, E.N. Oreshkin, V.N. Sergeev, Food industry, 1, 13-15 (2017)

2. V.M. Rodenzova, O.A. Vrzhezinskay, D.V. Risnik, D.B. Nikityk, V.A. Tutelyan, Voprosy Pitaniia, 86, 113-124 (2017)

3. V.L. Cheshinsky, Bakery products, 1, 16-17 (2018)

4. M.S. Ahmed, Foods and Raw Materials, 7, 42-50 (2019)

5. M.S. Gins, V.F. Pivovarov, V.K. Gins, P.F. Kononkov, N.M. Derkanosova, Russ. Vegetabl., 22, 4-9 (2014)

6. P.F. Kononkov, V.K. Gins, V.F. Pivovarov, M.S. Gins, M.S. Bunin, A.V Meshkov, V.I. Terechova, Vegetables as a functional food product (Metropolitan Printing House, Moscow, 2008)
7. N.I. Derkanosov, Development and evaluation of consumer properties of bakery products enriched with yacon, $\mathrm{PhD}$ dissertation (Orel, 2011)

8. T.N. Malytina, Development of modified technologies for liquid rye starter culture with stable performance, $\mathrm{PhD}$ dissertation (Voronezh, 2005)

9. O.V. Afanasyeva, Microbiology of the baking industry (Beresta, St. Petersburg, 2003)

10. N.M. Derkanosova, A.A. Zhuravlev, I.A. Sorokina, Modeling and optimization of technological processes of food production (Voronezh State Technical Academy, Voronezh, 2011)

11. Collection of technological instructions for the production of bread and bakery products (Moscow, 1989) 